\title{
Towards an analytical theory for charged hard spheres
}

\author{
L.Blum ${ }^{1}$, D.V.P.Veloz ${ }^{2}$ \\ ${ }^{1}$ Department of Mathematics, Hill Center, Busch Campus, Rutgers University, Piscataway, N.J. 08854 \\ 2 Department of Physics, Faculty of Natural Sciences, University of Puerto Rico, Rio Piedras, Puerto Rico \\ 00931
}

Received July 23, 2007

\begin{abstract}
Ion mixtures require an exclusion core to avoid collapse. The Debye Hueckel (DH) theory, where ions are point charges, is accurate only in the limit of infinite dilution. The mean spherical approximation (MSA) is the embedding of hard cores into $\mathrm{DH}$, and is valid for higher densities. The properties of any ionic mixture can be represented by the single screening parameter $\Gamma$ which for the equal ionic size restricted model is obtained from the Debye parameter $\kappa$. This $\Gamma$ representation, the binding mean spherical approximation (BIMSA), is also valid for complex / associating systems, such as the general $n$-polyelectrolytes. The BIMSA is the only theory that satisfies the infinite dilution limit of the $\mathrm{DH}$ theory for any chain length. Furthermore, the contact pair distribution function calculated from our theory agrees with the Monte Carlo of Bresme ea.(Phys. Rev. E, 1995, 51, 289).
\end{abstract}

Key words: electrolytes, MSA, ESMSA, contact pair distribution function

PACS: $61.20 . \mathrm{Gy}$

\section{Introduction}

Stable ionic mixtures require an exclusion core to avoid the collapse of the system. For this reason the Debye Hueckel $(\mathrm{DH})$ [1]theory, in which the ions are point particles, is accurate only in the limit of infinite dilution. The MSA [2-4] that is an embedding of the DH theory into the hard-core Ornstein Zernike (OZ) equation is valid for high densities, and is even asymptotically exact at infinite density [5]. In the MSA the properties of any ionic mixture can be represented by a single screening parameter $\Gamma[6]$ which in the simplest equal ionic size restricted model is obtained from the Debye screening parameter $\kappa$ :

$$
\Gamma=\frac{1}{2 \sigma}\{\sqrt{1+2 \kappa \sigma}-1\}
$$

$\kappa$ is the inverse of the Debye screening length defined by

$$
\kappa^{2}=\frac{4 \pi \beta e^{2}}{\epsilon} \sum_{k} \rho_{k} z_{k}^{2},
$$

where $z_{k}$ is the electrovalence, $\rho_{k}$ is the density of component $\mathrm{k}, \beta$ is the Boltzmann thermal factor, $\sigma_{k}$ is the hard core diameter, and $\epsilon$ is the dielectric constant. The one parameter representation [7] is valid for a number of complex and associating systems such as dimers, and even polymers, where as in the Debye-Hueckel theory, the thermodynamic properties depend on a single screening parameter $\Gamma$ : for the dimerization of equally charged hard ions we get

$$
\kappa^{2} \frac{\alpha+\Gamma \sigma}{1+\Gamma \sigma}=4 \Gamma^{2}(1+\Gamma \sigma)^{2} .
$$

After a detailed analysis [8-10] we can generalize equation (3) in the form

$$
\kappa^{2} \mathcal{F}(n, \alpha)=4 \Gamma^{2}(1+\Gamma \sigma)^{2} .
$$


For dimers

$$
\mathcal{F}(2, \alpha)=\frac{\alpha+\Gamma \sigma}{1+\Gamma \sigma} .
$$

In the limit of total association $\alpha=0$, and we recover the DH limiting law with the charge of the polyelectrolyte, for any $n \geqslant 3$. Then after a lengthy calculation

$$
\begin{aligned}
\lim _{\rho \rightarrow 0} \mathcal{F}(n, 0) \sim n^{2} ; & \text { correct DH limit, } \\
\lim _{\rho \rightarrow \infty} \mathcal{F}(n, 0) \sim n ; & \text { high density limit. }
\end{aligned}
$$

The criticality of ionic systems, initiated by M.E. Fisher and collaborators is still a subject of current interest. [11-13]. In the original discussion of this problem Fisher and Levin [11] used the DH [1] theory in combination with Bjerrum association [14]. It is clear that to get a mathematically well defined system all the ions need to have an exclusion core. Most of the subsequent work is directed at the inclusion of the excluded core in the nonlinear Coulomb and the association problem. In our own previous work [15] we used different combinations of the binding mean spherical approximation (BIMSA) [9,10] and various treatments of ion association, all derived from the work of Bjerrum [14]. The best agreement with computer simulations was obtained from the SISBIMSA treatment of the association constant (Jiang, Blum, Bernard, Prausnitz and Sandler [15]. In the SIS approximation of Stell et al [16] the chemical association constant is computed from the contact pair correlation function. A discussion of the merits of the different approximations was recently given by Aqua, Banerjee and Fisher [12]). The real problem here is that, as it has been shown by Wertheim for the associating systems, the classical virial expansion does not converge $[17,18]$ and a new MSA (the BIMSA), based on the Wertheim-Ornstein-Zernike equation (WOZ) has to be formulated. As has been shown elsewhere $[9,10]$, for dense systems, the scaling solution and the remarkably simple thermodynamics of the MSA applies to the new theories but with a renormalized screening constant, $\Gamma^{N}$. In the ESMSA the low density limits are also included [21]. The real issue is that we need an internally consistent procedure and therefore there is an open (big) question about their reliability and accuracy that we will try to answer.

\section{Theory}

Ever since the DH [1] theory was formulated, almost a century ago, there has been a steady effort in finding the ways to improve and extend the range of its multiple applications. Most of the theoretical effort has been dedicated to the inclusion of the hard exclusion core and the nonlinearity of the Poisson-Boltzmann equation. Now we know [5] that the MSA is asymptotically exact at very high densities. At lower densities the association limits yield exact conditions that are satisfied by closures of the Wertheim-Ornstein-Zernike equation: the exact DH limit at infinite dilution must contain the charges of the associated ions. As has been pointed out in this work, since the parameter space of these systems is large, we need to have an accurate, fully analytical theory for the properties of these systems. The general problem was discussed in the past by several authors (see for example [19]). In the recent work we have proposed a new theory, the ESMSA which could be such a theory, since there is only one screening parameter $\Gamma$, as in the MSA, but also the degree of dissociation, ionic diameters, effective dielectric constants enter in the calculation through the contact pair correlation function.

The most interesting feature of the MSA even for complex systems, is that, as in the DebyeHueckel theory, the thermodynamic properties depend on a single screening (scaling) parameter $\Gamma$ :

$$
4[\Gamma]^{2}(1+\Gamma \sigma)^{2}=\kappa^{2} \frac{(\alpha+\Gamma \sigma)}{(1+\Gamma \sigma)}
$$

$\kappa$ is the inverse of the Debye screening length defined by

$$
\kappa^{2}=\frac{4 \pi \beta e^{2}}{\epsilon} \sum_{k} \rho_{k} z_{k}^{2}
$$


and $\alpha$ is the degree of dissociation. The remarkable property of this equation is that it yields the correct asymptotic limits for zero density as well as for very large density [5], where

$$
\Gamma=\frac{1}{2 \sigma}\{\sqrt{1+2 \kappa \sigma}-1\} \sim\left\{\sqrt{\frac{\kappa}{2 \sigma}}\right\} .
$$

In the case of associating (polymerizing) ions the BIMSA for the restricted primitive model yields a very simple expression $\Gamma^{\mathrm{B}}$. This result applies to Polyelectrolytes and accounts for the remarkable agreement with the simulations of Orkulas et al. [20]. The question arises which is the best interpolation scheme between these two regimes? One possible answer can be obtained by testing different combinations as was done in our previous work [15]: However, it is clear that one cannot separate the sources of errors in the analysis of criticality. Slill, a more illuminating perspective can be obtained considering the simulations by Bresme et al [22], as we will see below. The usefulness of the MSA resides in the fact that the scaling solution is formally valid for the general mixture of the ions of arbitrary charge and size.

It has been shown by Rosenfeld and Blum (Y. Rosenfeld and L. Blum, [5] that the MSA is asymptotically exact at a very large density. However, the point remains that at low temperature $\mathcal{A} N Y$ theory based on the normal Ornstein Zernike (OZ) equation will fail, because it will not be capable of reaching the full association limits. This is corrected by the Wertheim Ornstein Zernike (WOZ) [18] equation, which has been shown to work remarkably well even for the limit of infinitely long polyelectrolyte chains [8].

For many applications it is important to have an analytical, but at the same time an accurate theory of electrolytes. This is not an easy task to carry out, but recent advances have made this an attainable goal. One important ingredient of this theory is presumably the contact pair correlation function $(\mathrm{PCF})$. In this communication we evaluate a simple functional form of the contact PCF, using the Monte Carlo simulations by Bresme et al. [22]. We find that the best analytical representation is obtained from this formula. It is increasingly erroneous at high charges. One possible reason for this failure is the fact that the simulations do not satisfy the PST, as is suggested by some preliminary simulation runs. Another source of errors is the neglect of the field parameter $\eta$.

\section{The contact pair distribution function}

In the present contribution we show that the contact pair distribution function for a hard ion mixture can be represented explicitly by a functional of $\Gamma[9,10,21]$ :

$$
g_{i j}^{00}\left(\sigma_{i j}\right)=g_{i j}^{\mathrm{HS}}\left(\sigma_{i j}\right) \mathrm{e}^{-\frac{\beta e^{2}}{\sigma_{i j} \epsilon_{0}} X_{i}^{01} X_{j}^{01}}, \quad X_{i}^{01}=\frac{z_{i}-\eta \sigma_{i}^{2}}{1+\Gamma \sigma_{i}} \simeq \frac{z_{i}}{1+\Gamma \sigma_{i}}
$$

$\eta$ is a mean field parameter which depends on many body interactions, such as $\alpha$, usually very small, and $\epsilon_{0}$ is an effective dielectric constant. The hard core contact correlation is from the Carnahan-Starling approximation [24]

$$
g_{i j}^{\mathrm{HS}}(\sigma)=\frac{1-\frac{\pi}{12} \sum_{i} \rho_{i} \sigma^{3}}{\left(1-\frac{\pi}{6} \sum_{i} \rho_{i} \sigma^{3}\right)^{3}}
$$

but in our case it can be taken to be 1 , since our system is very dilute.

Indeed the proper discussion of this system is to treat it as a mixture of ions and dipoles for the associated part [27]. For our restricted equal diameter problem we get

$$
\sigma_{i j}=\sigma_{i}=\sigma_{j}=\sigma
$$

The simplest approximation is to take $\eta=0$, which means that we neglect higher order correlation effects [10]. Then from equation (10) we get

$$
g_{i j}^{00}(\sigma)=\mathrm{e}^{-\frac{z_{i} z_{j} \beta e^{2}}{\varepsilon \sigma(1+\Gamma \sigma)^{2}}} .
$$




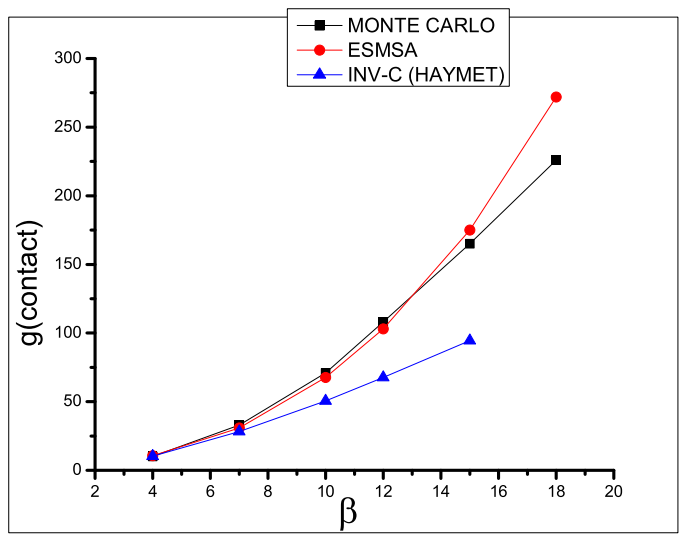

Figure 1. Comparison of the contact pair distribution function for $g_{+-}^{\text {ESMSA-BIMSA }}$. The squares are the Monte Carlo results by Bresme et al. [22]. The triangles are the INV-C theory of Haymet et al [25]. The circles are the ESMSA-BIMSA with $\eta=0$ and an effective dielectric constant of $\epsilon_{0}=1.17$ (which also depends on the association constant $\alpha$ ).

The results of the calculation are shown in figure 1. The agreement for $\frac{\beta e^{2}}{\sigma}$ up to 16 is quite good, and much better than the HNC theory [26] which does not easily converge or the INV-C of Duh and Haymet [25] which is shown in figure 1. However, in our theory the error in the last point is sizable, and we have no explanation for this at the time, other than the suspicion that this may be a consequence of the failure to satisfy the PST [23].

\section{Acknowledgements}

The authors are indebted to the NSF-PREM program for financial support. We wish a very happy 60th birthday to Prof. Fumio Hirata. 


\title{
References
}

1. Debye P., Hueckel E., Phys. Z., 1923, 24, 183.

2. Percus J.K., Yevick G., Phys. Rev., 1964, 110, 250.

3. Lebowitz J.L., Percus J.K., Phys. Rev., 1966, 144, 251.

4. Waisman E., J. L. Lebowitz, J. Chem. Phys., 1970, 52, 4307.

5. Rosenfeld Y., Blum L., J. Chem. Phys. , 1986, 85, 1556.

6. Blum L., Mol. Phys., 1975, 30, 1529.

7. Enriquez A., Blum L., Mol. Phys., 2005, 103, 3201.

8. Bernard O., Blum L., Proc. International School of Physics "Enrico Fermi", Course CLV, Mallamace F. and Stanley H.E. (Eds.), IOS Press, Amsterdam, 2004, 155, 335.

9. Bernard O., Blum L., J. Chem. Phys., 1996, 104, 4746.

10. BernardO., Blum L., J. Chem. Phys., 2000, 112, 7227.

11. M. Fisher E., Levin Y., Phys. Rev. Lett., 1993, 71, 3826.

12. Aqua J.-N., Banerjee S., Fisher M.E., Phys. Rev. E, 2005, 72, 041501:1-25.

13. Kim Y.C., Fisher M.E., Panagiotopoulos A.Z., Phys. Rev., 2005, 95, 195703:1-4.

14. Bjerrum N., Kgl. Dan. Vidensk. Selsk. Mat.-Fys. Medd., 1926, 7, 1.

15. Jiang J.W., Blum L., Bernard O., Prausnitz J.M., Sandler S.I., J. Chem. Phys., 2002, 116, 7977.

16. Stell G. et al. J. Chem. Phys., 1989, 91, 3618; J. Phys. Chem., 1996, 100, 1415; J. Chem. Phys., 1995, 102, 5785 .

17. Wertheim M.S., J. Stat. Phys., 1984, 35, 19:35; J. Stat. Phys., 1984, 42, 459:477.

18. Wertheim M.S., J. Chem. Phys., 1985, 85, 2929; J. Chem. Phys., 1987, 87, 7323; J. Chem. Phys., 1988, 88, 1214 .

19. Kalyuzhnyi Yu.V., Blum L., Holovko M.F., Protsykevytch I.A., Physica A, 1997, $236,85$.

20. Orkulas G., Kumar S., Panagiotopoulos A.Z., Phys. Rev. Letters, 2003, 90, 048303-25.

21. Blum L., Arias M., Mol. Phys., 2006, 104, 3801.

22. Bresme F., Lomba E., Weis J.J., Abascal J.L.F., Phys. Rev. E, 1995, 51, 289.

23. Blum L., Ch. Gruber, Lebowitz J.L., Martin Ph.A., Phys. Revs. Letters, 1982, 48, 1769.

24. Carnahan N.F., Starling K.E., J. Chem. Phys, 1969, 51, 635.

25. Duh D.M., Haymet A.D.J., J. Chem. Phys., 1992, 97, 7716.

26. Llano-Restrepo M., Chapman W.G., J. Chem. Phys., 1992, 97, 2046; J. Chem. Phys., 1994, 100, 5139.

27. Blum L., J. Chem. Phys., 2002, 117, 756.

\section{До аналітичної теорії заряджених твердих сфер}

\author{
Л.Блюм ${ }^{1}$, Д.В.П.Велоз ${ }^{2}$ \\ ${ }^{1}$ Математичний факультет, Університет Рутжер, Піскатавей, США \\ 2 Фізичний факультет, Університет Пуерто-Ріко, Пуерто-Ріко, США \\ Отримано 23 липня 2007 р.
}

\begin{abstract}
Щоб уникнути колапсу, іонні суміші вимагають включення в теорію твердого кору. Теорія ДебаяГюккеля (ДГ), в рамках якої іони вважаються точковими зарядами, є точною тільки в границі нескінченного розведення. Середньо-сферичне наближення, яке враховує твердий кор, є справедливим для більших густин. Властивості будь-якої іонної суміші можуть бути представлені за допомогою одного параметра Г, який для примітивної моделі іонів однакового розміру отримується з параметра Дебая $\kappa$. Це Г-представлення (BIMSA) має місце також для складних/асоційованих систем, таких як загальні n-поліелектроліти. BIMSA є єдиною теорією, яка задовільняє границі нескінченого розведення теорії ДГ для довільної довжини ланцюжка. Крім того, парна функція розподілу на контакті, обчислена в рамках нашої теорії, узгоджується з результатами Монте Карло Бресме та ін.(Phys. Rev. E, 1995, 51, 289).
\end{abstract}

Ключові слова: електроліти, середньо-сферичне наближення, парна функція розподілу на контакті

PACS: $61.20 . \mathrm{Gy}$ 
